Review

\title{
Review of Stimuli-Responsive Polymers in Drug Delivery and Textile Application
}

\author{
Sudipta CHATTERJEE and Patrick Chi-leung HUI *
}

Institute of Textiles and Clothing, The Hong Kong Polytechnic University, Hung Hom, Hong Kong

* Correspondence: tchuip@polyu.edu.hk; Tel.: +86-852-2766-6537

Academic Editors: Jessica Rosenholm and Constantinos Tsitsilianis

Received: 5 June 2019; Accepted: 11 July 2019; Published: 12 July 2019

\begin{abstract}
This review describes some commercially available stimuli-responsive polymers of natural and synthetic origin, and their applications in drug delivery and textiles. The polymers of natural origin such as chitosan, cellulose, albumin, and gelatin are found to show both thermo-responsive and $\mathrm{pH}$-responsive properties and these features of the biopolymers impart sensitivity to act differently under different temperatures and $\mathrm{pH}$ conditions. The stimuli-responsive characters of these natural polymers have been discussed in the review, and their respective applications in drug delivery and textile especially for textile-based transdermal therapy have been emphasized. Some practically important thermo-responsive polymers such as pluronic F127 (PF127) and poly( $N$-isopropylacrylamide) (pNIPAAm) of synthetic origin have been discussed in the review and they are of great importance commercially because of their in situ gel formation capacity. Some $\mathrm{pH}$-responsive synthetic polymers have been discussed depending on their surface charge, and their drug delivery and textile applications have been discussed in this review. The selected stimuli-responsive polymers of synthetic origin are commercially available. Above all, the applications of bio-based or synthetic stimuli-responsive polymers in textile-based transdermal therapy are given special regard apart from their general drug delivery applications. A special insight has been given for stimuli-responsive hydrogel drug delivery systems for textile-based transdermal therapy, which is critical for the treatment of skin disease atopic dermatitis.
\end{abstract}

Keywords: stimuli-responsive polymer; thermo-responsive; $\mathrm{pH}$-responsive; hydrogel; drug delivery; textile

\section{Introduction}

Hydrogels are three-dimensional polymeric networks made up of the same or different hydrophilic polymers and contain large amounts of water in their structure [1-3]. The polymeric backbone with hydrophilic functional groups hold a large amount of water in the structure and crosslinking network formed by polymeric chains, which resists its dissolution in water [4,5]. Hydrogels exhibit the ability to swell and possess some degree of flexibilities, which are very similar to the natural tissue due to their large water content. The compactness of hydrogels in aqueous media is maintained by physical cross-linking (e.g., entanglements, crystallites) and, also, chemical cross-linking [6,7]. Hydrogels widely vary in their composition, chemical structure, biodegradability, and various physio-chemical properties such as spectral and mechanical properties, $\mathrm{pH}$ stability, and, depending on all such factors, their biological function and performances vary in multiple dimensions [8-10]. Hydrogels resemble some physical properties of living tissues such as high-water content, compactness, and low interfacial tension with aqueous media, and those properties of hydrogels impart their great applicability in the bio-medical field, especially for drug delivery [11-14]. The biomedical applications of hydrogels including drug delivery, tissue engineering, clinical bandages, and biosensors come in the form of film/film forming systems, micro/nano-sphere, matrix, nanoparticles, and nanocomposites depending 
on the chemical composition and processing parameters of hydrogels [15-18]. The suitable use of hydrogels for delivering drugs can be upgraded by modifying their transport properties for drugs and also by chemical modification $[4,19]$.

The recent focus on functional polymers mostly centers around stimuli-responsive polymers and these polymers have attracted great attention since these can show sol-gel transitions in response to external triggers like temperature, $\mathrm{pH}$, and light $[20,21]$. Moreover, the physical changes in stimuli-responsive polymers are reversible and they are capable of returning to their initial state after the trigger is removed [21]. In recent years, there has been a remarkable growth in the development of stimuli-responsive polymer-based drug delivery systems with sustained and controlled drug release properties [22,23]. The important feature of stimuli-responsive polymers is the critical solution temperature (CST), which can be defined as a critical temperature at which the polymeric solution shows a phase separation, which moves from the isotropic state to the anisotropic state [21]. The polymer with lower critical solution temperature (LCST) shows the solution phase below CST and becomes insoluble or forms hydrogels over CST with heating [20]. The LSCT can be defined as a critical temperature at which the polymeric solution shows a phase separation, which moves from the isotropic state to the anisotropic state [21]. The polymers with LCST are mostly used for developing drug delivery systems [22]. Stimuli-responsive gelling materials constructed from natural and synthetic polymers are successfully used to develop drug delivery systems and regenerative medicine products because of their triggered actions in response to external stimuli [24-26]. The hydrogels made of stimuli-responsive polymers can show some physical changes like porosity, swelling with external stimuli, and the switchable physical properties provide huge and wide-spread biomedical applications of these polymers $[27,28]$. Thermo-responsive polymers show sol-gel transitions with a change in temperature of the external environment and hydrogels made of thermoresponsive polymers find tremendous drug delivery applications through simple chemical modifications [29-32], and some thermoresponsive polymers are capable of forming hydrogel near body temperature [33,34]. A part of thermoresponsive polymers show Arrhenius-type viscosity changes based on coil to globule transitions and others show enthalpic or entropic driven sol-gel transition [22,24]. The synthetic thermoresponsive polymers mainly poly(N-isopropylacrylamide) (pNIPAAm) and pluronic F127 (PF127) are widely used for drug delivery applications since they can form gels near the body temperature of $37^{\circ} \mathrm{C}$ [35-37]. The stimuli-responsive behavior of thermoresponsive polymers has been schematized in Figure 1 and this diagram of the thermoresponsive polymer having LCST shows sol-gel transition with the temperature. The phase change of thermoresponsive polymers in Figure 2 has been shown to be reversible where the polymer chains form hydrogel above LCST and the polymer chains are found to be in close proximity encapsulating a drug within it. The hydrogel reverts back to the sol phase when the temperature is below LCST and the polymers are soluble in the solvent mixture with no encapsulated drug (Figure 2). The swelling-shrinking behavior of $\mathrm{pH}$-responsive polymers in response to an external $\mathrm{pH}$ condition makes them suitable for drug delivery applications [38-40]. The cationic $\mathrm{pH}$ responsive polymers including chitosan, poly $(N, N$-dimethylaminoethyl methacrylate) (PDMAEMA), and poly $(N, N$-diethylaminoethyl methacrylate) (PDEAEMA) swell in acidic $\mathrm{pH}$ and shrink in basic $\mathrm{pH}$, where the basic $\mathrm{pH}$-responsive polymers such as albumin and polyacrylic acid (PAA) swell in basic $\mathrm{pH}$ and shrink in acidic $\mathrm{pH}[41,42]$. The stimuli-responsive behavior of $\mathrm{pH}$-responsive polymers has been presented in Figure 2 and this schematic diagram of $\mathrm{pH}$-responsive hydrogels gives an idea about the sensitivity of $\mathrm{pH}$-responsive polymers toward different external $\mathrm{pH}$ conditions. As shown in Figure 2, depending on the charge groups of $\mathrm{pH}$-responsive polymers, their hydrogels are found to change their swollen/shrinkage state in response to external $\mathrm{pH}$ of the media. 


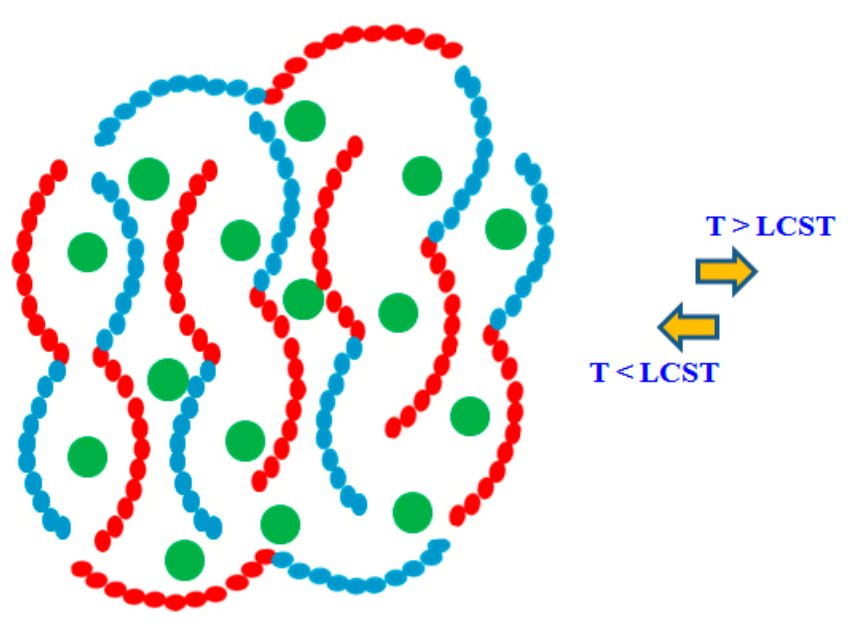

Polymer/drug in sol phase

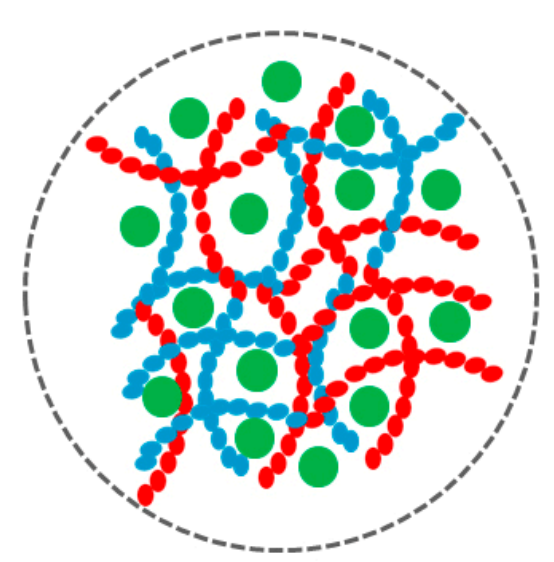

Drug loaded polymer in gel phase

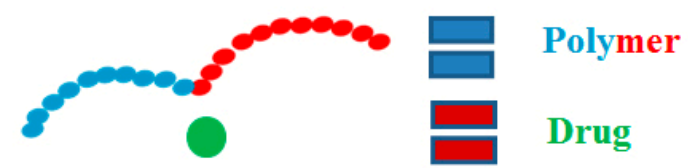

Figure 1. The schematic representation of thermo-responsive behavior (LCST) of the stimuli-responsive polymer hydrogel drug delivery system.

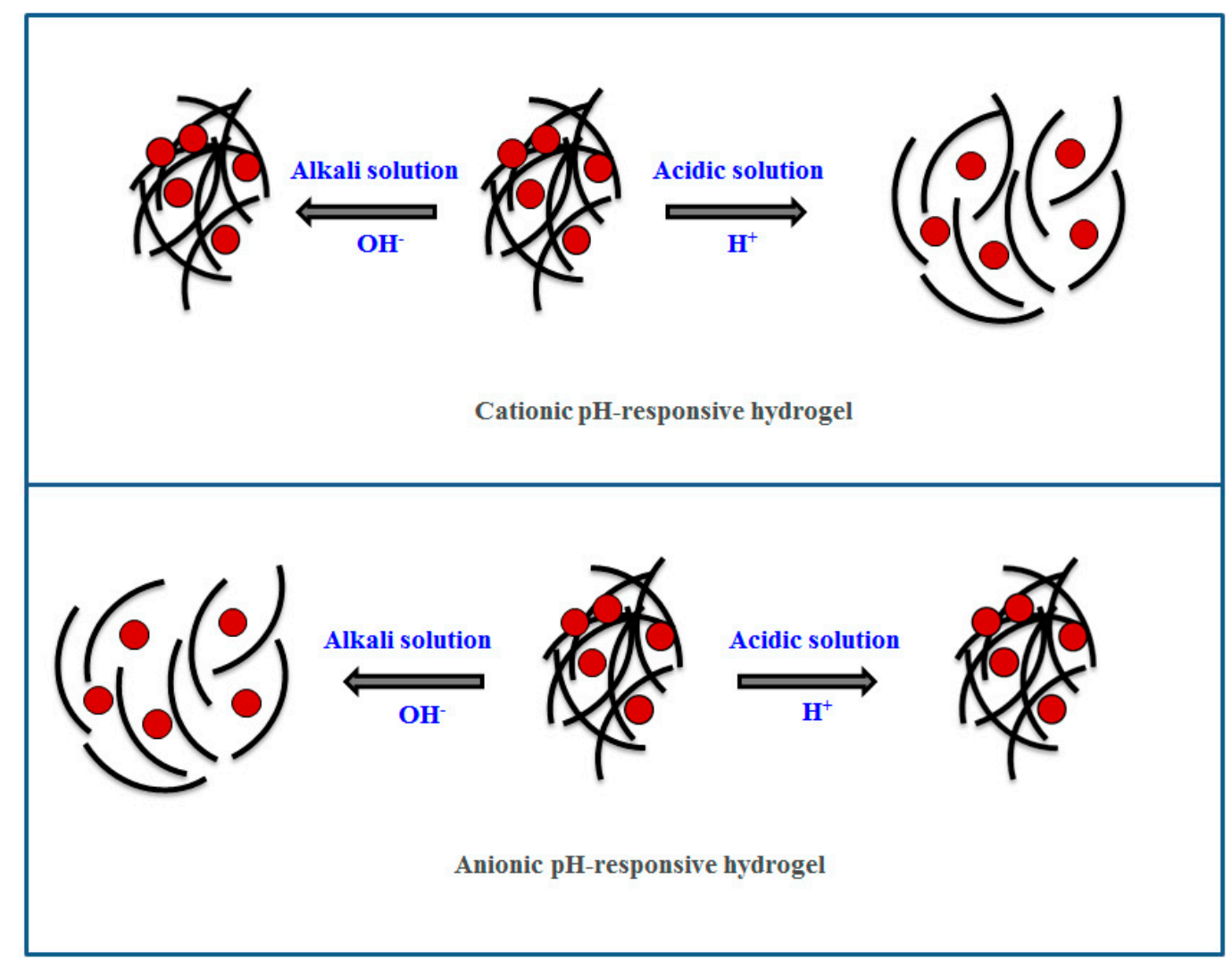

Figure 2. The schematic representation of $\mathrm{pH}$-responsive behavior of the stimuli-responsive polymer hydrogel drug delivery system. 
Textile-based transdermal therapy using drug loaded hydrogels made of stimuli-responsive polymers has become an effective means of skin care [35,43-45]. Wang et al. [43,44] developed PF127-based thermo-responsive hydrogels to load water soluble traditional Chinese drug Cortex moutan, which has been reported to be effective against pathogenesis related to atopic dermatitis and the transdermal therapy using their system seems to be an effective means to fight against this disease using smart textiles. The functionalized textiles coated with stimuli-responsive hydrogel can balance moisture on the skin and give comfort by actively balancing body temperature $[46,47]$. The functionalized textiles coated with stimuli-responsive hydrogels are enriched with soft display, aesthetic appeal, and improved wetting properties [48-50]. In this review, the drug delivery and textile applications of various stimuli-responsive polymers have been considered. The textile applications of stimuli-responsible polymers mainly focus on textile based transdermal therapy where drugs and moisture are simultaneously transferred to infected sites on the skin. The whole review has been divided into two parts: drug delivery and textile applications of natural stimuli-responsive polymers including chitosan, albumin, cellulose, gelatin, and those of synthetic polymers including PF127, pNIPAAm, poly(ethylene glycol) (PEG), polyacrylic acid (PAA), and poly(dimethylaminoethyl methacrylate) (PDMAEMA) and poly(diethylaminoethyl methacrylate) (PDEAEMA). Figure 3 highlights the main objective of the study and outlines the properties of stimuli-responsive polymers of biological and synthetic origin, and their biomedical applications in brief. The chemical structure of natural polymers are given in Figure 4. Figure 5 depicts the chemical structure of all synthetic polymers described in this case. The natural polymers are capable of showing both thermo-responsive and $\mathrm{pH}$-responsive properties as well as simple chemical modifications and composite formation with other polymers are applied to increase and improve their biomedical applications especially for drug delivery. Synthetic thermo-responsive polymers are well recognized for their in situ gel forming ability. Their simple chemical modifications and composite formations are applied using other polymers of natural or synthetic origin to increase their biocompatibility and reduce toxicity. The chemical nature, type of stimuli-responsiveness, and biomedical applications of all stimuli-responsive polymers are described in Table 1.

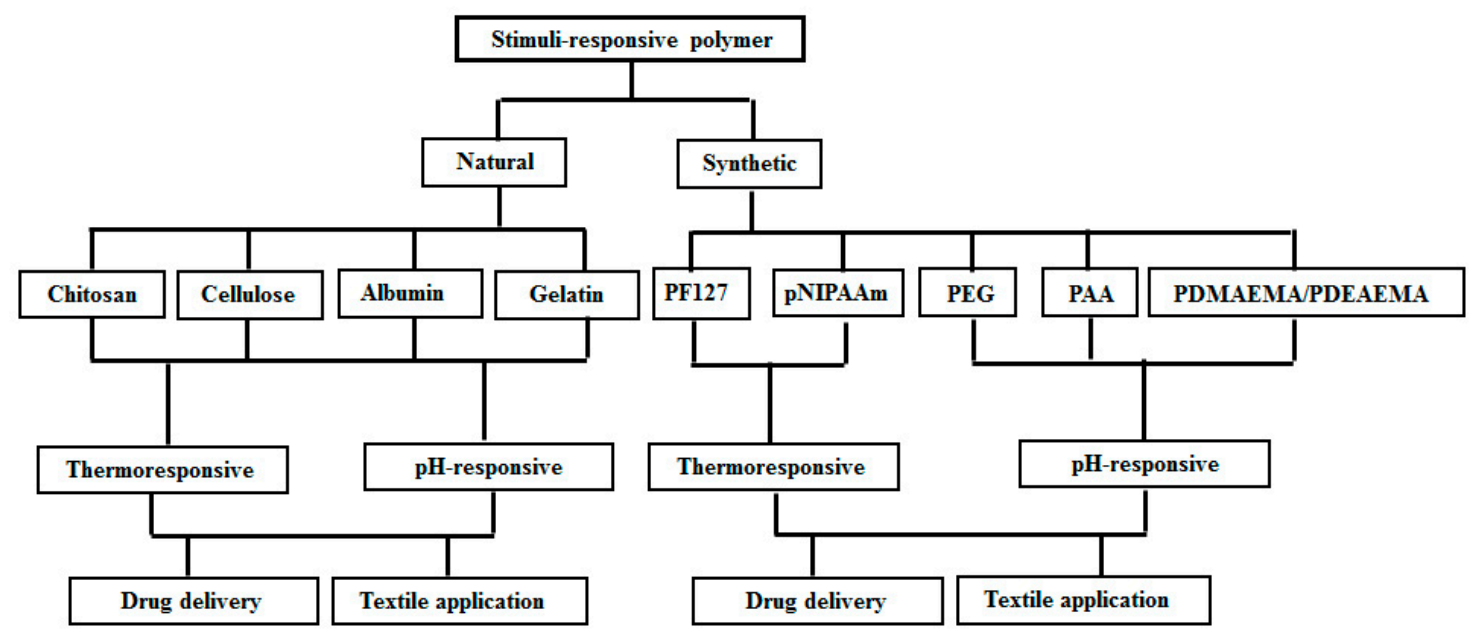

Figure 3. The flowchart outlining the selection of stimuli-responsive polymers and their applications. 


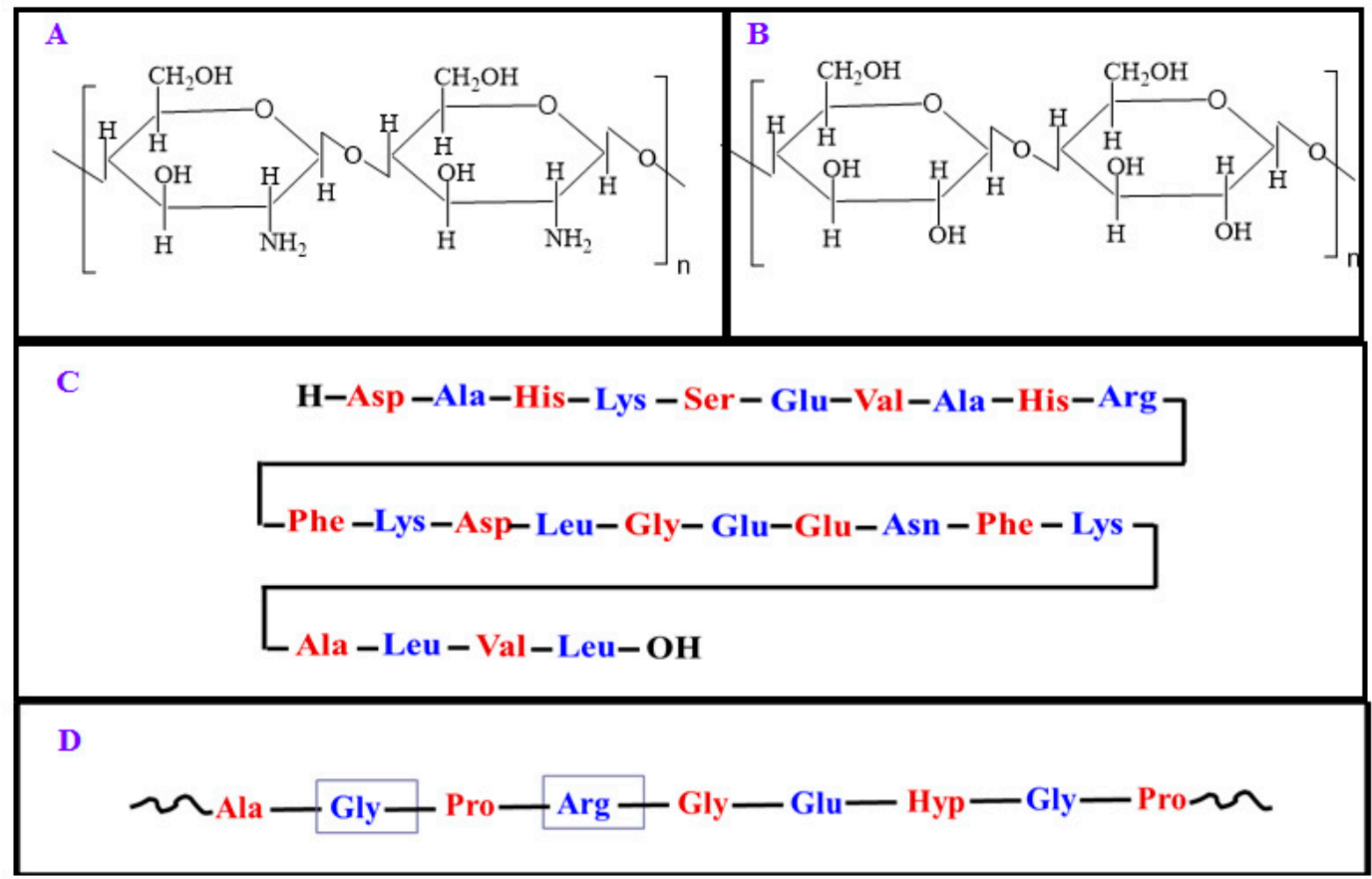

Figure 4. The chemical structures of the natural polymers, chitosan (A), cellulose (B), serum albumin (C), and gelatin (D).

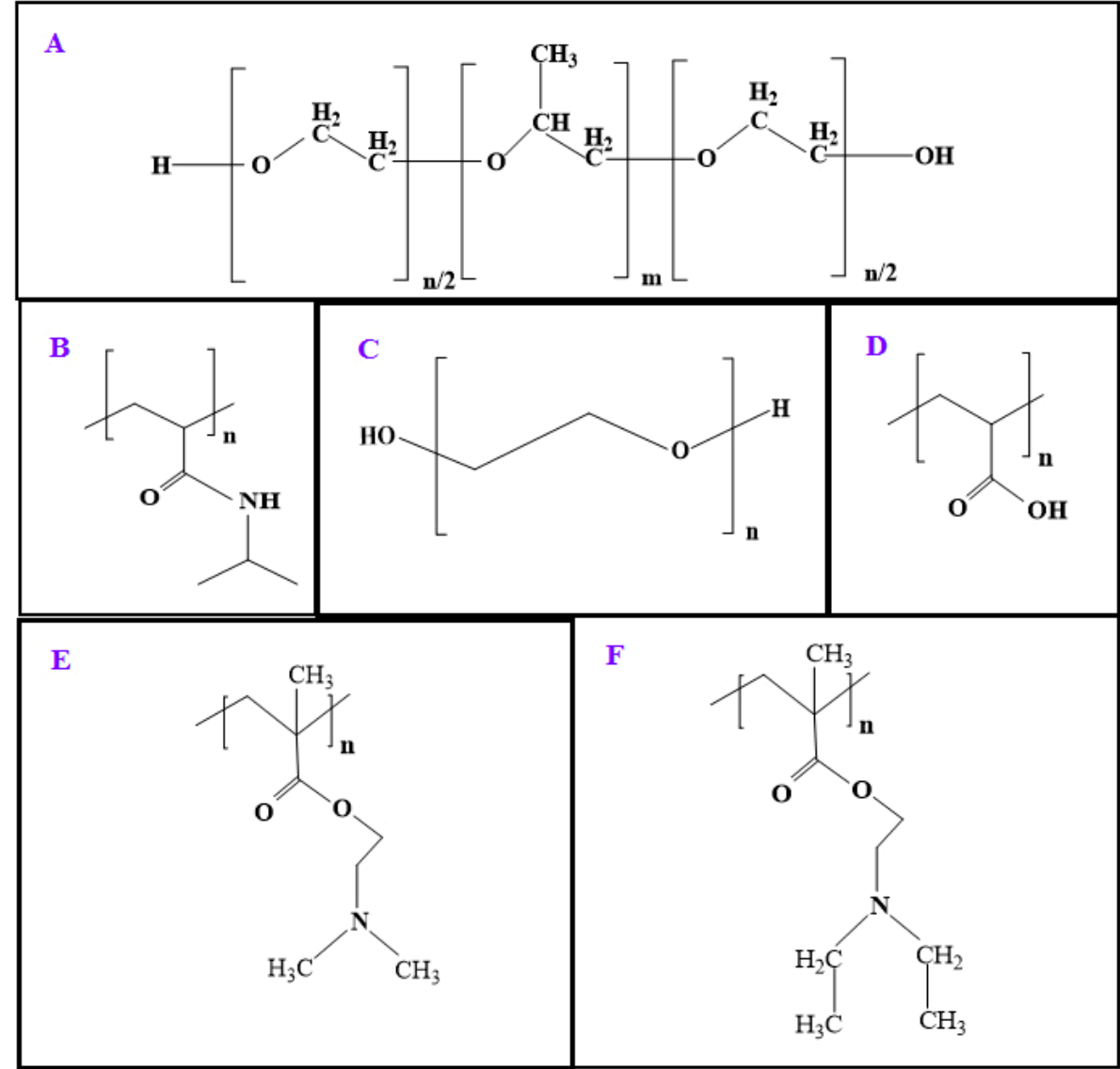

Figure 5. The chemical structure of the thermo-responsive synthetic polymers, PF127 (A), pNIPAAm (B), and the pH-responsive synthetic polymers, PEG (C), PAA (D), PDMAEMA (E), and PDEAEMA (F). 
Table 1. Chemical nature, type of stimuli-responsiveness, and biomedical applications of stimuli-responsive polymers.

\begin{tabular}{|c|c|c|c|}
\hline Polymer & Chemical Nature & $\begin{array}{c}\text { Type of } \\
\text { Stimuli-Responsiveness }\end{array}$ & Biomedical Applications \\
\hline Chitosan & Natural (polysaccharide) & $\begin{array}{c}\text { Thermo-responsive } \\
\text { pH-responsive }\end{array}$ & $\begin{array}{c}\text { Drug delivery, tissue } \\
\text { engineering, textile application }\end{array}$ \\
\hline Cellulose & Natural (polysaccharide) & $\begin{array}{l}\text { Thermo-responsive } \\
\text { pH-responsive }\end{array}$ & $\begin{array}{c}\text { Drug delivery, tissue } \\
\text { engineering, textile application }\end{array}$ \\
\hline Albumin & Natural (polypeptide) & $\begin{array}{l}\text { Thermo-responsive } \\
\text { pH-responsive }\end{array}$ & $\begin{array}{c}\text { Drug delivery, tissue } \\
\text { engineering, textile application }\end{array}$ \\
\hline Gelatin & Natural (polypeptide) & $\begin{array}{l}\text { Thermo-responsive } \\
\text { pH-responsive }\end{array}$ & $\begin{array}{c}\text { Drug delivery, tissue } \\
\text { engineering, textile application }\end{array}$ \\
\hline PF127 & Synthetic & $\begin{array}{l}\text { Thermo-responsive, } \\
\text { in-situ gel formation }\end{array}$ & $\begin{array}{l}\text { Drug delivery, textile based } \\
\text { transdermal therapy }\end{array}$ \\
\hline pNIPAAm & Synthetic & $\begin{array}{l}\text { Thermo-responsive, } \\
\text { in-situ gel formation }\end{array}$ & Drug delivery, textile application \\
\hline PEO & Synthetic & $\begin{array}{l}\mathrm{pH} \text {-responsive } \\
\quad \text { (neutral) }\end{array}$ & Drug delivery, textile application \\
\hline PAA & Synthetic & $\begin{array}{l}\mathrm{pH} \text {-responsive } \\
\quad \text { (anionic) }\end{array}$ & Drug delivery, textile application \\
\hline PDMAEMA/PDEAEMA & Synthetic & $\begin{array}{l}\mathrm{pH} \text {-responsive } \\
\text { (cationic) }\end{array}$ & Drug delivery, textile application \\
\hline
\end{tabular}

\section{Natural Stimuli-Responsive Polymers}

\subsection{Chitosan}

Chitosan as a natural stimuli-responsive polymer is capable of showing both thermo-responsive and $\mathrm{pH}$ responsive properties [51,52]. The drug delivery systems made of chitosan show relevance to drug delivery applications especially for cancer therapy and skin treatment due to their biocompatibility, biodegradability, and low toxicity [24]. The drug delivery system made of chitosan, hyaluronic acid, and pNIPAAm showed thermo-responsive property and was used for controlled delivery of analgesic drug nalbuphine [53]. The thermo-responsive hydrogel made of cross-linked chitosan and pNIPAAm via emulsion polymerization was applied as a drug delivery system for antibacterial drug levofloxacin [54]. The thermo-responsive hydrogel made by grafting pluronic onto chitosan was used as an injectable cell delivery system for cartilage regeneration [55]. The injectable thermo-reversible hydrogel made from PEG grafted chitosan was used for sustained release of drugs and the hydrogel system also showed a $\mathrm{pH}$-responsive property [56]. The drug delivery system made from chitosan and $\alpha \beta$-glycerophosphate exhibited a thermo-responsive property and was used as a drug delivery system for adriamycin and 6-mercaptopurine [57]. The thermo-responsive hydrogel made of pNIPAAm and chitosan was applied on cotton fabric using glutalraldehyde as a cross-linker to impart antibacterial activity to cotton fabric [58].

Chitosan due to its primary amine groups forms a cationic hydrogel network in water and it shows $\mathrm{pH}-$ responsive behavior by swelling in acidic $\mathrm{pH}(\mathrm{pH}<\mathrm{pKa})$ and shrinking in basic $\mathrm{pH}(\mathrm{pH}>$ pKa) [59]. The hydrogel formed from chitosan, acrylic acid, (2-dimethylamino) ethyl methacrylate via in situ free radical polymerization showed $\mathrm{pH}$-responsiveness with enhanced mechanical stability and was used as a drug delivery system for controlled delivery of bovine serum albumin and 5-fluorouracil in cancer therapy [60]. The bone ash-reinforced chitosan-based pH-responsive hydrogel loaded with model drug amoxicillin was applied for the treatment of gastric ulcer [61]. The hydrogel structure was fabricated by photopolymerization of chitosan-grafted-glycidyl methacrylate and poly(ethylene glycol)diacrylate under UV light [61]. The hydrogel with $\mathrm{pH}$ responsive character was developed from chitosan and poly(ethylene oxide) and applied for oral delivery of metronidazole and 
amoxicillin [62]. The pH-responsive hydrogel network was found to release more drugs in simulated gastric fluid than simulated intestinal fluid [62]. The $\mathrm{pH}$-responsive hydrogel made of chitosan and poly( $N$-vinyl-2-pyrrolidone) in the presence of $74 \%$ neutralized PAA was used for wound healing. It showed different extent of swelling depending on the $\mathrm{pH}$ of external media [63]. The $\mathrm{pH}$-responsive character of chitosan hydrogels was imparted on textile fabric by coating or integrating on it to develop smart textiles or medical textiles $[50,64]$.

\subsection{Cellulose}

Cellulose, which is the most abundant natural polymer on earth, is made up of glucose monomers and capable of forming hydrogel using their functional hydroxyl groups $[65,66]$. Methylcellulose, which is the functional material developed from cellulose, is water soluble and can show a thermo-responsive property with the sol-gel transition in the temperature range of 60 to $80{ }^{\circ} \mathrm{C}[24,67]$. The thermo-responsive hydrogel made from pNIPAAm and methylcellulose showed gel formation near the body temperature and the mechanical strength of the hydrogel was improved [68]. The thermo-responsive hydrogel from methylcellulose and PF127 was used as a drug delivery system for anti-cancer drug docetaxel and the system showed more sustained drug release than free docetaxel [69]. The thermo-responsive hydrogel from kappa-carrageenan and methylcellulose showed double thermal gel-sol-gel transition upon heating and was used for developing the drug delivery system [70]. The injectable bone substitute was prepared from the thermo-responsive hydrogel of methylcellulose, gelatin, and citric acid with a bio-ceramic powder loaded into it [71]. The injectable thermosensitive hydrogel from methylcellulose and chitosan was applied for tissue engineering and showed sol-gel transition near the body temperature of $37^{\circ} \mathrm{C}$ [72]. The carbomethyl cellulose, which is another functional derivative of cellulose, is capable of forming thermo-responsive hydrogel. The drug delivery system formed from carboxymethyl cellulose and gelatin showed sol-gel transition near the body temperature and was used for transdermal drug therapy with lidocaine [73]. The thermo-responsive hydrogel formed from carboxymethyl cellulose sodium and Poloxamer 407 was used as the drug delivery system for Chinese herbal medicine in textile-based transdermal therapy [43,44]. The hydrogel system with traditional Chinese medicine was mainly applied for the treatment of atopic dermatitis and the hydrogel with thermo-responsive property is capable of showing sol-gel transition near a body temperature of $37^{\circ} \mathrm{C}[43,44]$.

The stimuli-responsive hydrogels made from cellulose have been becoming popular for the last few years due to their biocompatibility and non-toxicity. The $\mathrm{pH}$-responsive hydrogel of cellulose was developed by simply mixing aqueous solutions of cellulose acetoacetate and cystamine dihydrochloride at room temperature and, moreover, this cellulose-based hydrogel showed dual responsiveness via reversible sol-gel transitions in response to both $\mathrm{pH}$ and redox triggers [74]. The cellulose-based hydrogels after epichlorohydrin mediated cross-linking of quaternized cellulose and carboxymethyl cellulose showed a $\mathrm{pH}$ responsive property along with salt responsiveness and the mass ratio of two cellulose-based compounds in the composites was varied to compare their $\mathrm{pH}$ and salt responsiveness [75]. These cellulose-based hydrogels are reported to have various biomedical applications including drug delivery and tissue engineering [75]. The hydrogel system made of carboxymethyl cellulose and pNIPAAm showed the $\mathrm{pH}$-responsive character along with thermo and redox responsiveness [76]. The multi-responsive hydrogel was used as a drug delivery system for lysozyme and the release of lysozyme from the system was studied at a different $\mathrm{pH}$, temperature, and redox environments to ensure its maximum effective drug delivery applications [76]. The $\mathrm{pH}$-responsive hydrogel made of hydroxyethyl cellulose and hyaluronic acid was used as a drug delivery system for the treatment of skin lesions and this transdermal drug delivery system loaded with isoliquiritigenin was found to be effective for the treatment of acne since it showed excellent permeability in the skin [77]. 


\subsection{Albumin}

Albumin, which is a natural globular protein commonly found in blood plasma, is capable of showing a stimuli-responsive property in response to external stimuli like temperature and $\mathrm{pH}$ [24]. The thermo-responsive hydrogel made from bovine serum albumin (BSA) and low molecular weight polyethylene glycol (PEG) showed sol-gel transition near the body temperature and it was reported to be a promising drug delivery material [78]. The $\mathrm{pH}$ responsive hydrogel developed by free radical polymerization of methacrylate bovine serum albumin and $N$-isopropylacrylamide was used as a drug delivery system for caffeine and theophylline [79]. The curcumin-loaded thermo-responsive nano-hydrogel was developed with BSA for ophthalmic treatment [80].

The anionic hydrogel forming albumin can show $\mathrm{pH}$-responsiveness by swelling in basic $\mathrm{pH}$ medium and shrinking in acidic $\mathrm{pH}[27,81]$. The $\mathrm{pH}$-responsive hydrogel developed from BSA with hydroxyethyl methacrylate and acrylic acid monomers was used as a drug delivery system for anti-cancer drug flutamide [82]. BSA-based $\mathrm{pH}$ responsive hydrogel formed by free radical polymerization was applied as a drug delivery system for oral delivery [83]. The drug delivery system based on the pH-responsive hydrogel from alginate and albumin was used for delivery of prednisolone [84]. BSA-based $\mathrm{pH}$-responsive hydrogels were coated on textile fabric to develop medical textiles for wound healing [85].

\subsection{Gelatin}

Gelatin, which is an animal origin natural protein, can show thermo-responsive properties and is commercially available in different form such as hydrogels, fibers, and nanoparticles [86]. The tunable thermo-responsive gelatin hydrogel showed volume transition near the body temperature and it was reported to be a promising drug delivery system [87]. The injectable thermo-responsive hydrogel made of chitosan and gelatin showed sol-gel transition near the body temperature and it showed compatibility with human tissue [88]. The thermo-responsive hydrogel system developed from chitosan, gelatin, and glycerol phosphate was applied as a cell carrier for nucleus pulposus regeneration [89]. The thermo-responsive hydrogel of gelatin and chondroitin sulphate was obtained by a simple method involving layer-by-layer (LbL) deposition and the system was developed with high mechanical strength, which improved its biomedical applications [90]. The thermo-responsive hydrogel made of carboxymethyl cellulose and gelatin copolymer was used as a drug delivery system with lidocaine in transdermal drug delivery and the system was used for percutaneous delivery of the drug [73].

The nanogel made of gelatin, $N, N^{\prime}$-ethylenebisacrylamide, and sodium methacrylate showed a $\mathrm{pH}$-responsive character and it was developed by a solvent-free emulsion polymerization method with sun flower seed oil as a continuous phase [91]. The gelatin-based nanogel was used as a drug carrier for diclofenac sodium salt [91]. The pH-responsive hydrogel was developed from gelatin and acrylic acid for colon-specific oral drug delivery using ketoprofen as a model drug [92]. The pH-responsive hydrogel of gelatin methacrylate was developed for the controlled delivery of gentamicin and ampicillin (Amp) and both drugs loaded into the hydrogel showed synergistic activity in killing multi drug resistant bacteria [93]. The gelatin-based $\mathrm{pH}$-responsive hydrogel was developed by grafting $\beta$-cyclodextrin to gelatin (Gel), which is followed by cross-linking with oxidized dextran and the hydrogel was used as a drug delivery system for anti-cancer drug 5-fluorouracil [94].

\section{Synthetic Stimuli-Responsive Polymers}

\subsection{Pluronic F127}

Pluronic F127 (PF127) is a non-ionic triblock copolymer of poly(ethylene oxide)-b-poly(propylene oxide)- $b$-poly(ethylene oxide) (PEO-PPO-PEO) and, being a thremo-responsive synthetic polymer, PF127 can form the hydrogel near the body temperature [35,95]. PF127 is approved by the 'U.S. Food and Drug Administration' (FDA) to be used in biomedical areas especially for drug delivery, 
tissue engineering, and the administration of the PF127-based drug delivery system, which can be oral, ocular, intranasal, subcutaneous, vaginal, and rectal [95]. For last few years, the potential drug delivery applications of PF127-based systems have been emerging for transdermal therapy [35]. The thermo-responsive hydrogel made of PF127 and hyaluronic acid showed gel formation at a body temperature of $37^{\circ} \mathrm{C}$ and was used as a drug delivery system for a human growth hormone [96]. The thermo-responsive hydrogel made of hyaluronic acid grafted PF127 showed in situ gel formation and was applied for delivery of model anti-cancer drugs cisplatin and carboplatin [97]. The drug delivery system made from thermo-responsive hydrogel of glycol chitosan and PF127 by photo-polymerization was applied for delivery of doxorubicin [98]. The biodegradable thermo-responsive composite hydrogel made of PF127 and PEG-poly(E-caprolactone)-PEG copolymer was applied as a drug delivery system for model drugs Vitamin $B_{12}$, honokiol, and BSA and the hydrogel showed sol-gel transition at the body temperature [99]. The thermo-responsive hydrogel made from chitosan and PF-127 was applied as a drug delivery system for model anti-cancer drug 5-fluorouracil [100]. The hydrogel system made of PF127 and Pluronic F68 was evaluated for in situ hydrogel formation under physiological conditions and the hydrogel made of PF127 (20 wt\%) was found to be capable of forming hydrogel under a physiological condition. However, the addition of Pluronic F68 to PF127 enhanced the gelation temperature and could not form hydrogels under physiological condition [101]. This thermo-responsive hydrogel was applied for ocular drug delivery [101]. The thermo-responsive hydrogel made of PF127 and alginate was applied as a drug delivery system of a model drug selegeline for transdermal therapy. The drug delivery system showed sustained and controlled release of selegeline [102]. The PF127-based thermo-responsive hydrogels were used in textile-based transdermal therapy for the treatment of AD. The hydrogels made of PF127 and carboxymethyl cellulose sodium were loaded with Chinese herbal medicine to deliver moisture and drugs simultaneously to infected sites on the skin [43,44].

\subsection{Poly(N-isopropylacrylamide)}

Poly(N-isopoprylacrilamide) (pNIPAAm), which is a synthetic thermo-responsive polymer can form hydrogel at or near the body temperature [103]. pNIPAAm is the mostly studied and FDA-approved, widely applied thermo-responsive polymer for drug delivery applications [24,104,105]. The thermo-responsive hydrogel made of pNIPAAm and PAA showed sol-gel transition near the body temperature and was used as a drug delivery system [106]. The hydrogel system also showed a pH-responsive property [107]. The thermo-responsive hydrogel made of pNIPAAm and methylcellulose showed gel formation at the body temperature and was used as a promising drug delivery system near the body temperature [68]. The hydrogel from pNIPAAm and butyl methacrylate (BuMA) showed a thermo-responsive property with zero order drug release profiles [108]. The thermo-responsive hydrogel made of pNIPAAm and alginate showed gel formation near the body temperature and was used as a drug delivery system for anti-cancer drug doxorubicin [109]. The thermo-responsive hydrogel made of pNIPAAm and cellulose nanocrystals via free-radical polymerization showed gel formation within a range of 36 to $39{ }^{\circ} \mathrm{C}$ and was loaded with model drug metronidazole for a wound dressing purpose [110]. The thermo-responsive hydrogel made of pNIPAAm and PEG-diacrylate showed in situ gel formation and was applied for ocular drug delivery with model drugs immunoglobulin-G and BSA [111]. The thermo-responsive hydrogel of pNIPAAm and spiropyran formed by a facile and versatile surface-initiated controlled polymerization method (SI-ARGET-ATRP) showed the capability of dimensional changes on cotton fabric upon irradiation with visible light or a temperature stimulus [112]. The thermo-responsive nano-hydrogel made of pNIPAAm and chitosan was applied on cotton fabric as a surface modifying system and the nanohydrogel also showed pH-responsiveness [113]. Thermo-responsive pNIPAAm was grafted onto cotton fabric to modify the surface property of the fabric, which was dependent on the temperature during the grafting process, and this was applied to develop smart textiles for clinical applications [114]. 


\subsection{Poly(ethylene glycol) (PEG)}

Poly(ethylene glycol) (PEG) is a water-soluble synthetic polymer with excellent biocompatibility and no-toxicity, and shows a $\mathrm{pH}$-responsive property in response to an external $\mathrm{pH}$ change [115]. The $\mathrm{pH}$-responsive hydrogel made of the co-polymeric network of PEG and poly(methacrylic acid) was used for oral delivery of model drug oxaliplatin and it was used for colon targeting of the drug [116]. The $\mathrm{pH}$-responsive hydrogel made of the PEG derivative and $\alpha, \beta$-polyaspartylhydrazide was applied as a drug delivery system for anti-cancer drug doxorubicin [117]. The drug delivery system made of PEG and cholesterol-modified poly(monomethyl itaconate) showed a pH-responsive property and was used for controlled and targeted release of the model drug piroxicam, which was used in tumor-targeting chemotherapy [118]. The pH-responsive hydrogel from PEG and poly(itaconic acid) was developed using UV-initiated free radical polymerization with tetraethylene glycol as the cross-linking agent and Irgacure 2959 as the initiator and it was used as a drug delivery system for oral delivery of the drug [119]. The pH-responsive nanoparticles made of PEG-poly(L-histidine)-poly(L-lactide) were used as drug carriers for anti-tumor drug doxorubicin [120]. The $\mathrm{pH}-$ responsive micellar drug delivery system made of acetal-linked poly(ethylene glycol)-block-polylactide copolymer was applied for delivery of anti-cancer drug paclitaxel [121]. The $\mathrm{pH}$-responsive hydrogel made of PEG and chitosan was applied on the cotton membrane to develop medical textiles for wound dressing [122].

\subsection{Polyacrylic Acid}

Polyacrylic acid (PAA), which is an anionic synthetic compound, can form pH-responsive hydrogel, swells/dissolves at $\mathrm{pH}$ higher than its $\mathrm{pKa}$, and remains collapsed at acidic $\mathrm{pH}(\mathrm{pH}<\mathrm{pKa})$ [123]. This $\mathrm{pH}$ responsive behavior of PAA attributes to oral delivery of the drug by the PAA-based drug delivery system [124]. The $\mathrm{pH}$-responsive anionic hydrogels made of PAA can protect drugs from degradation and denaturation at a low $\mathrm{pH}$ of gastric juice and release drugs in specific locations, such as the upper small intestine and colon [125]. The pH-responsive PAA-based hydrogel cross-linked by poly(L-glutamic acid)-g-(2-hydroxyl methacrylamide) showed $\mathrm{pH}$-dependent swelling-shrinking behaviors and was used for the delivery of the model protein BSA [126]. The $\mathrm{pH}$ and thermo-responsive micelles developed from the block copolymer of PAA and pNIPAAM (pNIPAAm- $b$-PAA) was used as a drug delivery system for anti-cancer drug doxorubicin [127]. The $\mathrm{pH}$-triggered oral drug delivery system was developed by capping mesoporous silica SBA-15 with $\mathrm{pH}$-responsive polymer PAA via a facile graft-onto strategy and it was used to deliver anti-cancer drug doxorubicin for the treatment of colon cancer [128]. The pH-responsive biodegradable hydrogels made from four types of $\mathrm{pH}$-sensitive PAA derivatives and poly(L-glutamic acid) as a cross-linker were applied for oral delivery of insulin [129]. The pH-responsive hydrogel made of polyvinyl acetate cross-linked PAA was applied on textile fabric to develop wound healing monitoring textiles [130].

\subsection{Poly(N,N-dialkylaminoethyl methacrylate) and Eudragit}

Poly $(N, N$-dimethylaminoethyl methacrylate) (PDMAEMA) and poly $(N, N$-diethylaminoethyl methacrylate) (PDEAEMA), which are both cationic $\mathrm{pH}$-responsive polymers and swell in acidic $\mathrm{pH}(\mathrm{pH}<\mathrm{pKa})$ due to the protonation of their tertiary amine groups [131]. The $\mathrm{pH}$-responsive hydrogels formed by PDMAEMA and PDEAEMA find drug delivery applications since they can change the swelling-deswelling state in response to change in body $\mathrm{pH}$, especially in the gastro-intestinal environment of the human body [132]. The $\mathrm{pH}$-responsive hydrogel made of block co-polymer of poly(dimethysiloxane) and PDMAEMA was applied to deliver anticancer drug doxorubicin and the block co-polymer (poly(dimethysiloxane)-b-PDMAEMA) was synthesized by atom transfer radical polymerization (ATRP) [133]. The $\mathrm{pH}$-responsive hydrogel made of poly(vinyl alcohol) and PDMAEMA was used for drug delivery applications [134]. The structural hydrogels having a semi-interpenetrating network with different molecular weights were used to deliver riboflavin and PDMAEMA played a vital role in the swelling under different $\mathrm{pH}$ conditions [134]. The $\mathrm{pH}$-responsive nano-hydrogel was 
synthesized by copolymerization of PDEAEMA with hetero-bifunctional PEG bearing a 4-vinylbenzyl group at one end and a carboxylic acid group at the other end. The nano-hydrogel was used as a drug delivery system for anti-cancer drug doxorubicin [135]. The $\mathrm{pH}-$ responsive micelles from the copolymers of ethyl cellulose-graft-PDEAEMA through atom transfer radical polymerization were applied as the drug delivery system for model drug rifampicin [136]. The $\mathrm{pH}$-responsive PDMAEMA was grafted onto the cotton surface to develop medical textiles for low adherent wound dressing [137].

Eudragit prepared by the polymerization of acrylic and methacrylic acids or their esters was first introduced commercially in 1950 by Röhm GmbH \& Co. KG-Germany. Eudragit RL and Eudragit RS are anionic copolymers of acrylic and methacrylic acid esters having quaternary ammonium groups and used as anionic $\mathrm{pH}$-responsive polymers for mainly oral delivery of the drug [138]. The chemical structure of Eudragit RL and Eudragit RS has been given in Figure 6. pH-responsive nanoparticles made of Eudragit RL 100 and Eudragit RL 100-poly(lactic-co-glycolic acid) were used as drug delivery systems for diclofenac sodium in an intestinal $\mathrm{pH}$ condition of 6.8 [139]. The microspheres made of pH-responsive Eudragit RS100 were used as a drug delivery system for acidic drug ibuprofen [140]. Eudragit S100 as a pH-responsive polymer was coated onto the liposomes by a fast and organic solvent-free method for the colonic delivery of curcumin [141]. The transparent film formed from Eudragit E100 polymer was used for transdermal therapy since it showed good adhesion to the skin [142]. The loaded drug nicorandil was released due to erosion of hydrophilic Eudragit E100 polymer and the release of the drug was observed to be $100 \%$ within 20 min [142].

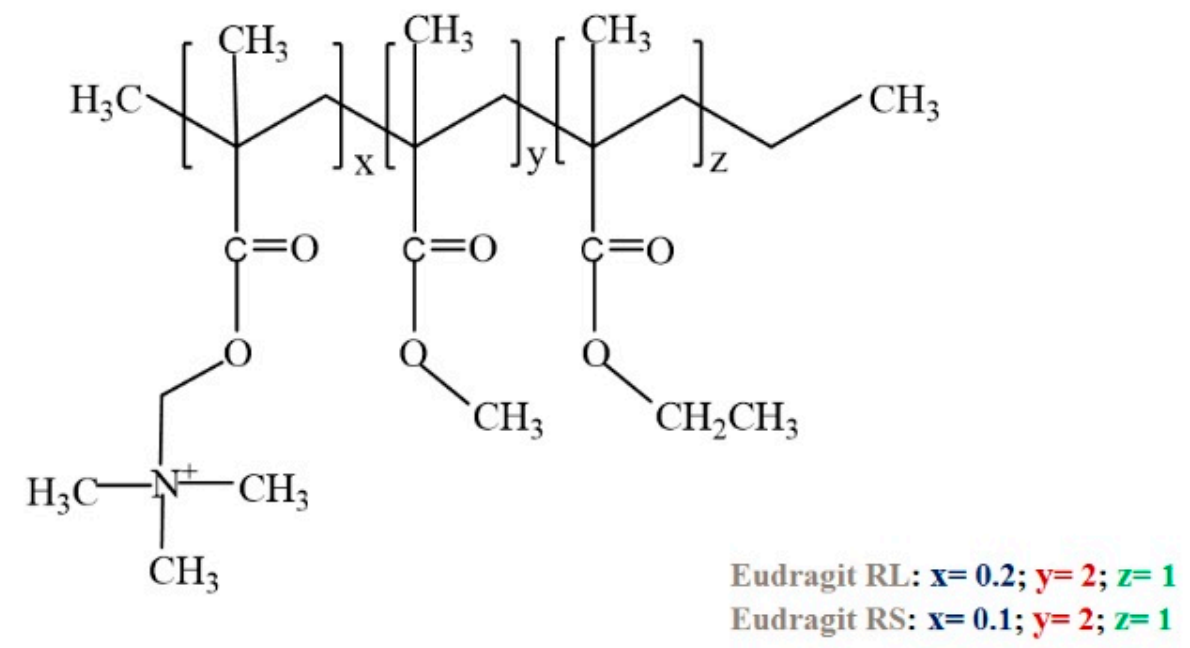

Figure 6. The chemical structure of Eudragit RL and RS.

\section{Conclusions}

Some stimuli-responsive polymers have made a significant contribution in the area of drug delivery. The stimuli-responsive polymers of natural origin such as chitosan, cellulose, albumin, and gelation are capable of showing both thermo-responsive and $\mathrm{pH}$-responsive characters. Their stimuli-responsive properties are highly recommended for drug delivery applications, and also in textile-based transdermal therapies. Some synthetic thermo-responsive polymers such as PF127 and pNIPAAm are capable of in situ gel formation, and their drug delivery applications have earned extremely high commercial importance. PF127 is now being successfully applied for transdermal therapy based on textiles. $\mathrm{pH}$-responsive polymers vary in their surface charges, and, depending on the surface charge, their mode and site of applications vary. The $\mathrm{pH}$-responsive polymers are useful for developing drug delivery systems and being used for transdermal therapies. In this review, some natural polymers (chitosan, cellulose, albumin, and gelatin) with both thermo-responsive and $\mathrm{pH}$-responsive characters are discussed and their drug delivery and textile applications are mentioned. The drug delivery and textile applications of some synthetic thermo-responsive (PF127 and pNIPAAm) and pH-responsive polymers 
(PEG, PAA, and PDMAEMA/PDEAEMA) have been discussed, which gives a special emphasis on their applications in textile-based transdermal therapy. The stimuli-responsive hydrogel-based drug delivery systems are already proven effective for the treatment of skin disease atopic dermatitis via textile-based transdermal therapy.

The stimuli-responsive polymers highlighted in this review are commercially available and their biomedical applications, especially for drug delivery, are well documented. However, their applications in textile-based transdermal therapy need further and more extensive research since many factors like skin $\mathrm{pH}$ and temperature come into play, as these factors are found to be varied depending on the physiological state of a person. Furthermore, the stability of drug delivery systems upon contact with skin is a major hurdle since the hydrogels of some thermo-responsive polymers like PF127 completely disintegrate under an acidic condition. Additionally, skin pH around 5.5 is good enough to destabilize the PF127-based hydrogel system. Therefore, more experiments are required to enhance $\mathrm{pH}$ stability of such drug carriers for successful application in transdermal therapy via textiles.

Funding: The study was supported by the project (1-ZVLM).

Acknowledgments: The Block Grant of the Faculty of Applied Science and Textiles, The Hong Kong Polytechnic University (Ref: 1-ZVLM), supported this study.

Conflicts of Interest: The authors declare no conflicts of interest.

\section{References}

1. Hoffman, A.S. Hydrogels for biomedical applications. Adv. Drug Deliver. Rev. 2002, 43, 3-12. [CrossRef]

2. Varaprasad, K.; Raghavendra, G.M.; Jayaramudu, T.; Yallapu, M.M.; Sadiku, R. Amini review on hydrogels classification and recent developments in miscellaneous applications. Mat. Sci. Eng. C-Mater. 2017, 79, 958-971. [CrossRef] [PubMed]

3. Wichterle, O.; Lím, D. Hydrophilic gels for biological use. Nature 1960, 185, 117-118. [CrossRef]

4. Ahmed, E.M. Hydrogel: Preparation, characterization, and applications: A review. J. Adv. Res. 2015, 6, 105-121. [CrossRef] [PubMed]

5. Ferreira, N.N.; Ferreira, L.M.B.; Cardoso, V.M.O.; Boni, F.I.; Souza, A.L.R.; Gremião, M.P.D. Recent advances in smart hydrogels for biomedical applications: From self-assembly to functional approaches. Eur. Polym. J. 2018, 99, 117-133. [CrossRef]

6. Buwalda, S.J.; Boere, K.W.M.; Dijkstra, P.J.; Feijen, J.; Vermonden, T.; Hennink, W.E. Hydrogels in a historical perspective: From simple networks to smart materials. J. Control. Release. 2014, 190, 254-273. [CrossRef] [PubMed]

7. Dragan, E.S. Design and applications of interpenetrating polymer network hydrogels. A review. Chem. Eng. J. 2014, 243, 572-590. [CrossRef]

8. Peak, C.W.; Wilker, J.J.; Schmidt, G. A review on tough and sticky hydrogels. Colloid Polym. Sci. 2013, 291, 2031-2047. [CrossRef]

9. Chai, Q.; Jiao, Y.; Yu, X. Hydrogels for biomedical applications: Their characteristics and the mechanisms behind them. Gels 2017, 3, 6. [CrossRef]

10. Li, J.; Mooney, D.J. Designing hydrogels for controlled drug delivery. Nat. Rev. Mater. 2016, 1, 16071. [CrossRef]

11. Tsitsilianis, C. Responsive reversible hydrogels from associative "smart" macromolecules. Soft Matter 2010, 6, 2372-2388. [CrossRef]

12. Peppas, N.A.; Wood, K.M.; Blanchette, J.O. Hydrogels for oral delivery of therapeuticproteins. Expert Opin. Biol. Ther. 2004, 4, 1-7. [CrossRef] [PubMed]

13. Sharpe, L.A.; Daily, A.M.; Horava, S.D.; Peppas, N.A. Therapeutic applications of hydrogels in oral drug delivery. Expert Opin. Drug Del. 2014, 11, 901-915. [CrossRef] [PubMed]

14. Narayanaswamy, R.; Torchilin, V.P. Hydrogels and their applications in targeted drug delivery. Molecules 2019, 24, 603. [CrossRef] [PubMed]

15. Caló, E.; Khutoryanskiy, V.V. Biomedical applications of hydrogels: A review of patents and commercial products. Eur. Polym. J. 2015, 65, 252-267. [CrossRef] 
16. Mastropietro, D.J.; Omidian, H.; Park, K. Drug delivery applications for superporous hydrogels. Expert Opin. Drug Del. 2012, 9, 71-89. [CrossRef] [PubMed]

17. Hanafy, N.A.N.; Leporatti, S.; El-Kemary, M.A. Mucoadhesive hydrogel nanoparticles as smart biomedical drug delivery system. Appl. Sci. 2019, 9, 825. [CrossRef]

18. Ahmed, T.A.; El-Say, K.M. Transdermal film-loaded finasteride microplates to enhance drug skin permeation: Two-step optimization study. Eur. J. Pharm. Sci. 2016, 88, 246-256. [CrossRef]

19. Hoare, T.R.; Kohane, D.S. Hydrogels in drug delivery: Progress and challenges. Polymer 2008, 49, $1993-2007$. [CrossRef]

20. Koetting, M.C.; Peters, J.T.; Steichen, S.D.; Peppas, N.A. Stimulus-responsive hydrogels: Theory, modern advances, and applications. Mater. Sci. Eng. 2015, 93, 1-49. [CrossRef]

21. Jeong, B.; Kibbey, M.R.; Birnbaum, J.C.; Won, Y.Y.; Gutowska, A. Thermogelling biodegradable polymers with hydrophilic backbones: PEG-g-PLGA. Macromolecules 2000, 33, 8317-8322. [CrossRef]

22. Kuckling, D. Stimuli-responsive gels. Gels 2018, 4, 60. [CrossRef] [PubMed]

23. Raza, A.; Rasheed, T.; Nabeel, F.; Hayat, U.; Bilal, M.; Iqbal, H.M.N. Endogenous and exogenous stimuli-responsive drug delivery systems for programmed site-specific release. Molecules 2019, 24, 1117. [CrossRef] [PubMed]

24. Klouda, L.; Mikos, A.G. Thermoresponsive hydrogels in biomedical applications. Eur. J. Pharm. Biopharm. 2008, 68, 34-45. [CrossRef] [PubMed]

25. Hoffman, A.S. Stimuli-responsive polymers: Biomedical applications and challenges for clinical translation. Adv. Drug Deliver. Rev. 2013, 65, 10-16. [CrossRef] [PubMed]

26. Alsuraifi, A.; Curtis, A.; Lamprou, D.A.; Hoskins, C. Stimuli responsive polymeric systems for cancer therapy. Pharmaceutics 2018, 10, 136. [CrossRef] [PubMed]

27. Sood, N.; Bhardwaj, A.; Mehta, S.; Mehta, A. Stimuli-responsive hydrogels in drug delivery and tissue engineering. Drug Deliv. 2016, 23, 748-770. [CrossRef] [PubMed]

28. Ding, C.; Tong, L.; Feng, J.; Fu, J. Recent advances in stimuli-responsive release function drug delivery systems for tumor treatment. Molecules 2016, 21, 1715. [CrossRef] [PubMed]

29. Zha, L.; Banik, B.; Alexis, F. Stimulus responsive nanogels for drug delivery. Soft Matter 2011, 7, 5908-5916. [CrossRef]

30. Jeong, B.; Kim, S.W.; Bae, Y.H. Thermosensitive sol-gel reversible hydrogels. Adv. Drug Deliver. Rev. 2002, 54, 37-51. [CrossRef]

31. Gandhi, A.; Paul, A.; Sen, S.O.; Sen, K.K. Studies on thermoresponsive polymers: Phase behaviour, drug delivery and biomedical applications. Asian J. Pharm. Sci. 2015, 10, 99-107. [CrossRef]

32. Gong, C.; Qi, T.; Wei, X.; Qu, Y.; Wu, Q.; Luo, F.; Qian, Z. Thermosensitive polymeric hydrogels as drug delivery systems. Curr. Med. Chem. 2013, 20,79-94. [CrossRef]

33. Ruel-Gariépy, E.; Leroux, J. In situ-forming hydrogels-review of temperature-sensitive systems. Eur. J. Pharm. Biopharm. 2004, 58, 409-426. [CrossRef]

34. Klouda, L.; Perkins, K.R.; Watson, B.M.; Hacker, M.C.; Bryant, S.J.; Raphael, R.M.; Kasper, F.K.; Mikos, A.G. Thermoresponsive, in situ crosslinkable hydrogels based on $N$-isopropylacrylamide: Fabrication, characterization and mesenchymal stem cell Encapsulation. Acta Biomater. 2011, 7, 1460-1467. [CrossRef] [PubMed]

35. Chatterjee, S.; Hui, P.C.-1.; Kan, C.-W. Thermoresponsive hydrogels and their biomedical applications: Special insight into their applications in textile based transdermal therapy. Polymers-Basel 2018, 10, 480. [CrossRef]

36. Bajpai, A.K.; Shukla, S.K.; Bhanu, S.; Kankane, S. Responsive polymers in controlled drug delivery. Prog. Polym. Sci. 2008, 33, 1088-1118. [CrossRef]

37. Tang, S.; Floy, M.; Bhandari, R.; Sunkara, M.; Morris, A.J.; Dziubla, X.; Hilt, O.Z. Synthesis and characterization of thermoresponsive hydrogels Based on $N$-Isopropylacrylamide crosslinked with 4,4'-dihydroxybiphenyl diacrylate. ACS Omega 2017, 2, 8723-8729. [CrossRef] [PubMed]

38. Jeong, B.; Kibbey, M.R.; Birnbaum, J.C.; Won, Y.Y.; Gutowska, A. pH-responsive hydrogels: Swelling model. Adv. Exp. Med. Biol. 2004, 553, 29-43.

39. Xu, L.; Qiu, L.; Sheng, Y.; Sun, Y.; Deng, L.; Li, X.; Bradley, M.; Zhang, R. Biodegradable pH-responsive hydrogels for controlled dual-drug release. J. Mater. Chem. B. 2018, 6, 510-517. [CrossRef] 
40. Hibbins, A.R.; Kumar, P.; Choonara, Y.E.; Kondiah, P.P.D.; Marimuthu, T.; Toit, L.C.d.; Pillay, V. Design of a versatile $\mathrm{pH}$-responsive hydrogel for potential oral delivery of gastric-sensitive bioactives. Polymers-Basel 2017, 9, 474. [CrossRef]

41. Gupta, P.; Vermani, K.; Garg, S. Hydrogels: From controlled release to $\mathrm{pH}$-responsive drug delivery. Drug Discov. Today 2002, 7, 569-579. [CrossRef]

42. Yoshida, T.; Lai, T.C.; Kwon, G.S.; Sako, K. pH- and ion-sensitive polymers for drug delivery. Expert Opin. Drug Del. 2013, 10, 1497-1513. [CrossRef] [PubMed]

43. Wang, W.; Wat, E.; Hui, P.C.L.; Chan, B.; Ng, F.S.F.; Kan, C.-W.; Wang, X.; Hu, H.; Wong, E.C.W.; Lau, C.B.S.; et al. Dual-functional transdermal drug delivery system with controllable drug loading based on thermosensitive poloxamer hydrogel for atopic dermatitis treatment. Sci. Rep. UK 2016, 6, 24112. [CrossRef] [PubMed]

44. Wang, W.; Hui, P.C.L.; Wat, E.; Chan, B.; Ng, F.S.F.; Kan, C.-W.; Lau, C.B.S.; Leung, P.-C. Enhanced transdermal permeability via constructing the porous structure of poloxamer-based hydrogel. Polymers-Basel 2016, 8, 406. [CrossRef] [PubMed]

45. Wang, W.; Hui, P.C.L.; Kan, C.W. Functionalized textile based therapy for the treatment of atopic dermatitis. Coatings 2017, 7, 82. [CrossRef]

46. Wang, X.; Hu, H.; Yang, Z.; He, L.; Kong, Y.; Fei, B.; Xin, J.H. Smart hydrogel-functionalized textile system with moisture management property for skin application. Smart Mater. Struct. 2014, 23, 125027. [CrossRef]

47. Hu, J.; Meng, H.; Li, G.; Ibekwe, S. A review of stimuli-responsive polymers for smart textile applications. Smart Mater. Struct. 2012, 21, 053001. [CrossRef]

48. Liu, B.; Hu, J. The application of temperature-sensitive hydrogels to textiles: A review of Chinese and Japanese investigations. Fibres Text. East. Eur. 2005, 13, 45-49.

49. Wang, J.; Zhong, Q.; Wu, J.; Chen, T. Thermo-responsive textiles. In Handbook of Smart Textiles; Tao, X., Ed.; Springer Science + Business Media: Singapore, 2015; ISBN 978-981-4451-46-8.

50. Chatterjee, S.; Hui, P.C.-L. Stimuli-responsive hydrogels: An interdisciplinary review. In Hydrogels - Smart Materials for Biomedical Applications; Popa, L., Ghica, M.V., Dinu-Pîrvu, C.-E., Eds.; IntechOpen: London, UK, 2018; ISBN 978-1-78985-876-1.

51. Chuang, C.-Y.; Don, T.-M.; Chiu, W.-Y. Synthesis of chitosan-based thermo- and pH-responsive porous nanoparticles by temperature-dependent self-assembly method and their application in drug release. $J$. Polym. Sci. A1. 2009, 47, 5126-5136. [CrossRef]

52. Fathi, M.; Zangabad, P.S.; Majidi, S.; Barar, J.; Erfan-Niya, H.; Omidi, Y. Stimuli-responsive chitosan-based nanocarriers for cancer therapy. Bioimpacts 2017, 7, 269-277. [CrossRef]

53. Fang, J.Y.; Chen, J.P.; Leu, Y.L.; Hu, J.W. Temperature-sensitive hydrogels composed of chitosan and hyaluronic acid as injectable carriers for drug delivery. Eur. J. Pharm. Biopharm. 2008, 68, 626-636. [CrossRef] [PubMed]

54. Shin, B.; Kim, J.; Vales, T.P.; Yang, S.K.; Kim, J.-K.; Sohn, H.; Kim, H.-J. Thermoresponsive drug controlled release from chitosan-based hydrogel embedded with poly( $N$-isopropylacrylamide) nanogels. J. Polym. Sci. A1. 2018, 56, 1907-1914. [CrossRef]

55. Park, K.M.; Lee, S.Y.; Joung, Y.K.; Na, J.S.; Lee, M.C.; Park, K.D. Thermosensitive chitosan-pluronic hydrogel as an injectable cell delivery carrier for cartilage regeneration. Acta Biomater. 2009, 5, 1956-1965. [CrossRef]

56. Bhattarai, N.; Matsen, F.A.; Zhang, M. PEG-grafted chitosan as an injectable thermoreversible hydrogel. Macromol. Biosci. 2005, 5, 107-111. [CrossRef] [PubMed]

57. Zhou, H.Y.; Chen, X.G.; Kong, M.; Liu, C.S.; Cha, D.S.; Kennedy, J.F. Effect of molecular weight and degree of chitosan deacetylation on the preparation and characteristics of chitosan thermosensitive hydrogel as a delivery system. Carbohyd. Polym. 2008, 73, 265-273. [CrossRef]

58. Wang, B.; Wu, X.; Li, J.; Hao, X.; Lin, J.; Cheng, D.; Lu, Y. Thermosensitive behavior and antibacterial activity of cotton fabric modified with a chitosan-poly(N-isopropylacrylamide) interpenetrating polymer network hydrogel. Polymers-Basel 2016, 8, 110. [CrossRef] [PubMed]

59. Mao, J.; Kondu, S.; Ji, H.F.; McShane, M.J. Study of the near-neutral pH-sensitivity of chitosan/gelatin hydrogels by turbidimetry and microcantilever deflection. Biotechnol. Bioeng. 2006, 95, 333-341. [CrossRef] [PubMed]

60. Che, Y.J.; Li, D.; Liu, Y.; Ma, Q.; Tan, Y.; Yue, Q.; Meng, F. Physically cross-linked pH-responsive chitosan-based hydrogels with enhanced mechanical performance for controlled drug delivery. RSC Adv. 2016, 6, 106035-106045. [CrossRef] 
61. Aycan, D.; Alemdar, N. Development of $\mathrm{pH}$-responsive chitosan-based hydrogel modified with bone ash for controlled release of amoxicillin. Carbohyd. Polym. 2018, 184, 401-407. [CrossRef]

62. Patel, V.R.; Amiji, M.M. Preparation and characterization of freeze-dried chitosan-poly(ethylene oxide) hydrogels for site-specific antibiotic delivery in the stomach. Pharm. Res. 1996, 13, 588-593. [CrossRef]

63. Rasool, A.; Ata, S.; Islam, A. Stimuli responsive biopolymer (chitosan) based blend hydrogels for wound healing application. Carbohyd. Polym. 2019, 203, 423-429. [CrossRef] [PubMed]

64. Kamoun, E.A.; Kenawy, E.-R.S.; Chen, X.A. review on polymeric hydrogel membranes for wound dressing applications: PVA-based hydrogel dressings. J. Adv. Res. 2017, 8, 217-233. [CrossRef] [PubMed]

65. Chang, C.; Zhang, L. Cellulose-based hydrogels: Present status and application prospects. Carbohydr. Polym. 2011, 84, 40-53. [CrossRef]

66. Gopi, S.; Balakrishnan, P.; Geethamma, V.G.; Pius, A.; Thomas, S. Applications of cellulose nanofibrils in drug delivery. In Applications of Nanocomposite Materials in Drug Delivery; Woodhead Publishing Series in Biomaterials: Arlington, TX, USA, 2018; pp. 75-95. ISBN 9780128137581.

67. Li, L.; Shan, H.; Yue, C.Y.; Lam, Y.C.; Tam, K.C.; Hu, X. Thermally induced association and dissociation of methylcellulose in aqueous solutions. Langmuir 2002, 18, 7291-7298. [CrossRef]

68. Liu, W.; Zhang, B.; Lu, W.W.; Li, X.; Zhu, D.; Yao, K.D.; Wang, Q.; Zhao, C.; Wang, C. A rapid temperature-responsive sol-gel reversible poly( $N$-isopropylacrylamide)-g-methylcellulose copolymer hydrogel. Biomaterials 2004, 25, 3005-3012. [CrossRef]

69. Kim, J.K.; Won, Y.W.; Lim, K.S.; Kim, Y.H. Low-molecular-weight methylcellulose-based thermo-reversible gel/pluronic micelle combination system for local and sustained docetaxel delivery. Pharmaceut. Res. 2012, 2, 525-534. [CrossRef]

70. Tomsic, M.; Prossnigg, F.; Glatter, O. A thermoreversible double gel: Characterization of a methylcellulose and kappa-carrageenan mixed system in water by SAXS, DSC and rheology. J. Colloid Interface Sci. 2008, 322, 41-50. [CrossRef]

71. Oğuz, Ö.D.; Ege, D. Rheological and mechanical properties of thermoresponsive methylcellulose/calcium phosphate-based injectable bone substitutes. Materials 2018, 11, 604. [CrossRef]

72. Tang, Y.F.; Wang, X.Y.; Li, Y.; Lei, M.; Du, Y.; Kennedy, J.F.; Knill, C.J. Production and characterisation of novel injectable chitosan/methylcellulose/salt blend hydrogels with potential application as tissue engineering scaffolds. Carbohyd. Polym. 2010, 82, 833-841. [CrossRef]

73. Nayak, A.; Babla, H.; Han, T.; Das, D.B. Lidocaine carboxymethylcellulose with gelatine co-polymer hydrogel delivery by combined microneedle and ultrasound. Drug Deliv. 2016, 23, 668-679. [CrossRef]

74. Liu, H.; Rong, L.; Wang, B.; Xie, R.; Sui, X.; Xu, H.; Zhang, L. Facile fabrication of redox/pH dual stimuli responsive cellulose hydrogel. Carbohyd. Polym. 2017, 176, 299-306. [CrossRef] [PubMed]

75. Chang, C.; He, M.; Zhou, J.; Zhang, L. Swelling behaviors of pH- and salt-responsive cellulose-based hydrogels. Macromolecules 2011, 44, 1642-1648. [CrossRef]

76. Dutta, S.; Samanta, P.; Dhara, D. Temperature, $\mathrm{pH}$ and redox responsive cellulose based hydrogels for protein delivery. Int. J. Biol. Macromol. 2016, 87, 92-100. [CrossRef] [PubMed]

77. Kwon, S.S.; Kong, B.J.; Park, S.N. Physicochemical properties of pH-sensitive hydrogels based on hydroxyethyl cellulose-hyaluronic acid and for applications as transdermal delivery systems for skin lesions. Eur. J. Pharm. Biopharm. 2015, 92, 146-154. [CrossRef] [PubMed]

78. Wang, K.; Buschle-Diller, G.; Wu, Y. Thermoresponsive hydrogels from BSA esterified with low molecular weight PEG. J. Appl. Polym. Sci. 2014, 131, 40946. [CrossRef]

79. Iemma, F.; Spizzirri, U.G.; Puoci, F.; Cirillo, G.; Curcio, M.; Parisi, O.I.; Picci, N. Synthesis and release profile analysis of thermo-sensitive albumin hydrogels. Colloid. Polym. Sci. 2009, 287, 779-787. [CrossRef]

80. Lou, J.; Hu, W.; Tian, R.; Zhang, H.; Jia, Y.; Zhang, J.; Zhang, L. Optimization and evaluation of a thermoresponsive ophthalmic in situ gel containing curcumin-loaded albumin nanoparticles. Int. J. Nanomed. 2014, 9, 2517-2525.

81. Raja, S.T.K.; Thiruselvi, T.; Mandal, A.B.; Gnanamani, A. pH and redox sensitive albumin hydrogel: A self-derived biomaterial. Sci. Rep. UK. 2015, 5, 15977. [CrossRef]

82. El-Sherif, H.; El-Masry, M.; Taleb, M.F.A. pH-sensitive hydrogels based on bovine serum albumin for anticancer drug delivery. J. Appl. Polym. Sci. 2010, 115, 2050-2059. [CrossRef] 
83. Iemma, F.; Spizzirri, U.G.; Puoci, F.; Muzzalupo, R.; Trombino, S.; Cassano, R.; Leta, S.; Picci, N. pH-sensitive hydrogels based on bovine serum albumin for oral drug delivery. Int. J. Pharmaceut. 2006, 312, 151-157. [CrossRef]

84. Oliveira, K.A.L.d.; Sitta, D.L.A.; Guilherme, M.R.; Muniz, E.C.; Rubira, A.F. Design of pH-responsive albumin-alginate hydrogels for drug delivery. J. Control. Release 2017, 259, e5. [CrossRef]

85. Pinho, E.; Soares, G. Functionalization of cotton cellulose for improved wound healing. J. Mater. Chem. B 2018, 6, 1887-1898. [CrossRef]

86. Asghar, A.; Henrickson, R.L. Chemical, biochemical, functional, and nutritional characteristics of collagen in food systems. Adv. Food Res. 1982, 28, 231-372. [PubMed]

87. Gandhi, S.S.; Yan, H.; Kim, C. Thermoresponsive gelatin nanogels. ACS Macro Lett. 2014, 3, $1210-1214$. [CrossRef]

88. Chang, Y.; Xiao, L.; Tang, Q. Preparation and characterization of a novel thermosensitive hydrogel based on chitosan and gelatin blends. J. Appl. Polym. Sci. 2009, 113, 400-407. [CrossRef]

89. Cheng, Y.-H.; Yang, S.-H.; Su, W.-Y.; Chen, Y.C.; Yang, K.C.; Cheng, W.T.; Wu, S.C.; Lin, F.H. Thermosensitive chitosan-gelatin-glycerol phosphate hydrogels as a cell carrier for nucleus pulposus regeneration: An in vitro study. Tissue Eng. Pt. A 2010, 16, 695-703. [CrossRef] [PubMed]

90. Criado, M.; Rey, J.M.; Mijangos, C.M.; Hernández, R. Double-membrane thermoresponsive hydrogels from gelatin and chondroitin sulphate with enhanced mechanical properties. RSC Adv. 2016, 6, 105821-105826. [CrossRef]

91. Curcio, M.; Altimari, I.; Spizzirri, U.G.; Cirillo, G.; Vittorio, O.; Puoci, F.; Picci, N.; Iemma, F. Biodegradable gelatin-based nanospheres as pH-responsive drug delivery systems. J. Nanopart. Res. 2013, 15, 1581. [CrossRef]

92. Raafat, A.I. Gelatin based pH-sensitive hydrogels for colon-specific oral drug delivery: Synthesis, characterization, and in vitro release study. J. Appl. Polym. Sci. 2010, 118, 2642-2649. [CrossRef]

93. Anirudhan, T.S.; Mohan, A.M. Novel pH sensitive dual drug loaded-gelatin methacrylate/methacrylic acid hydrogel for the controlled release of antibiotics. Int. J. Biol. Macromol. 2018, 110, 167-178. [CrossRef]

94. Anirudhan, T.S.; Mohan, A.M. Novel pH switchable gelatin based hydrogel for the controlled delivery of the anticancer drug 5-fluorouracil. RSC Adv. 2014, 4, 12109-12118. [CrossRef]

95. Akash, M.S.H.; Rehman, K. Recent progress in biomedical applications of pluronic (PF127): Pharmaceutical perspectives. J. Control. Release 2015, 209, 120-138. [CrossRef] [PubMed]

96. Kim, M.R.; Park, T.G. Temperature-responsive and degradable hyaluronic acid/pluronic composite hydrogels for controlled release of human growth hormone. J. Control. Release 2002, 80, 69-77. [CrossRef]

97. Hsu, S.H.; Leu, Y.L.; Hu, J.W.; Fang, J.Y. Physicochemical characterization and drug release of thermosensitive hydrogels composed of a hyaluronic acid/pluronic f127 graft. Chem. Pharm. Bull. 2009, 57, 53-58. [CrossRef] [PubMed]

98. Liu, Z.; Yao, P. Versatile injectable supramolecular hydrogels containing drug loaded micelles for delivery of various drugs. Polym. Chem. 2014, 5, 1072-1081. [CrossRef]

99. Gong, C.Y.; Shi, S.; Dong, P.W.; Zheng, X.L.; Fu, S.Z.; Guo, G.; Yang, J.L.; Wei, Y.Q.; Qian, Z.Y. In vitro drug release behavior from a novel thermosensitive composite hydrogel based on Pluronic f127 and poly(ethylene glycol)-poly(E-caprolactone)-poly(ethylene glycol) copolymer. BMC Biotechnol. 2009, 9, 8. [CrossRef] [PubMed]

100. Rokhade, A.P.; Shelke, N.B.; Patil, S.A.; Aminabhavi, T.M. Novel hydrogel microspheres of chitosan and pluronic F-127 for controlled release of 5-fluorouracil. J. Microencapsul. 2007, 24, 274-288. [CrossRef] [PubMed]

101. Khateb, K.A.; Ozhmukhametova, E.K.; Mussin, M.N.; Seilkhanov, S.K.; Rakhypbekov, T.K.; Lau, W.M.; Khutoryanskiy, V.V. In situ gelling systems based on Pluronic F127/Pluronic F68 formulations for ocular drug delivery. Int. J. Pharm. 2016, 502, 70-79. [CrossRef] [PubMed]

102. Chen, C.C.; Fang, C.L.; Al-Suwayeh, S.A.; Leu, Y.L.; Fang, J.Y. Transdermal delivery of selegiline from alginate-pluronic composite thermogels. Int. J. Pharm. 2011, 415, 119-128. [CrossRef]

103. Hacker, M.C.; Klouda, L.; Ma, B.B.; Kretlow, J.D.; Mikos, A.G. Synthesis and characterization of injectable, thermally and chemically gelable, amphiphilic poly( $N$-isopropylacrylamide)-based macromers. Biomacromolecules 2008, 9, 1558-1570. [CrossRef] 
104. Moghadam, S.; Larson, R.G. Assessing the efficacy of poly( $N$-isopropylacrylamide) for drug delivery applications using molecular dynamics simulations. Mol. Pharm. 2017, 14, 478-491. [CrossRef] [PubMed]

105. Gulyuz, U.; Okay, O. Self-healing poly(N-isopropylacrylamide) hydrogels. Eur. Polym. J. 2015, 72, 12-22. [CrossRef]

106. Kulkarni, S.S.; Aloorkar, N.H. Smart polymers in drug delivery: An overview. J. Pharm. Res. 2010, 3, 100-108.

107. Yin, X.; Hoffman, A.S.; Stayton, P.S. Poly(N-isopropylacrylamide-co-propylacrylic acid) copolymers that respond sharply to temperature and pH. Biomacromolecules 2006, 7, 1381-1385. [CrossRef] [PubMed]

108. Okuyama, Y.; Yoshida, R.; Sakai, K.; Okano, T.; Sakurai, Y. Swelling controlled zero-order and sigmoidal drug release from thermoresponsive poly( $N$-isopropylacrylamide-co-butyl methacrylate) hydrogel. J. Biomater. Sci. Polym. Ed. 1993, 4, 545-556. [CrossRef] [PubMed]

109. Liu, M.; Song, X.; Wen, Y.; Zhu, J.L.; Li, J. Injectable thermoresponsive hydrogel formed by alginate-g-poly(N-isopropylacrylamide) that releases doxorubicin-encapsulated micelles as a smart drug delivery system. ACS Appl. Mater. Interfaces 2017, 9, 35673-35682. [CrossRef] [PubMed]

110. Zubik, K.; Singhsa, P.; Wang, Y.; Manuspiya, H.; Narain, R. Thermo-responsive poly(N-Isopropylacrylamide)cellulose nanocrystals hybrid hydrogels for wound dressing. Polymers-Basel 2017, 9, 119. [CrossRef] [PubMed]

111. Derwent, J.J.K.; Mieler, W.F. Thermoresponsive hydrogels as a new ocular drug delivery platform to the posterior segment of the eye. Trans. Am. Ophthalmol. Soc. 2008, 106, 206-214.

112. Schiphorst, J.T.; Broek, M.v.d.; Koning, T.d.; Murphy, J.N.; Schenning, A.P.H.J.; Esteves, A.C.C. Dual light and temperature responsive cotton fabric functionalized with a surface-grafted spiropyran-NIPAAm-hydrogel. J. Mater. Chem. A 2016, 4, 8676-8681. [CrossRef]

113. Bashari, A.; Hemmatinejad, N.; Pourjavadi, A. Surface modification of cotton fabric with dual-responsive PNIPAAm/chitosan nano hydrogel. Polym. Adv. Technol. 2013, 24, 797-806. [CrossRef]

114. Jiang, C.; Wang, Q.; Wang, T. Thermoresponsive PNIPAAm-modified cotton fabric surfaces that switch between superhydrophilicity and superhydrophobicity. Appl. Surf. Sci. 2012, 258, 4888-4892. [CrossRef]

115. Huang, H.; Hou, L.; Zhu, F.; Li, J.; Xu, M. Controllable thermal and pH responsive behavior of PEG based hydrogels and applications for dye adsorption and release. RSC Adv. 2018, 8, 9334-9343. [CrossRef]

116. Barkat, K.; Ahmad, M.; Minhas, M.U.; Khakid, I.; Nasir, B. Development and characterization of pH-responsive polyethylene glycol-co-poly(methacrylic acid)polymeric network system for colon target delivery of oxaliplatin: Its acute oral toxicity study. Adv. Polym. Technol. 2018, 37, 1806-1822. [CrossRef]

117. Li, L.; Gu, J.; Zhang, J.; Xie, Z.; Lu, Y.; Shen, L.; Dong, Q.; Wang, Y. Injectable and biodegradable pH-responsive hydrogels for localized and sustained treatment of human fibrosarcoma. ACS Appl. Mater. Interfaces 2015, 7, 8033-8040. [CrossRef] [PubMed]

118. Pourmoazzen, Z.; Bagheri, M.; Entezami, A.A.; Koshki, K.N. pH-responsive micelles composed of poly(ethylene glycol) and cholesterol-modified poly(monomethyl itaconate) as a nanocarrier for controlled and targeted release of piroxicam. J. Polym. Res. 2013, 20, 295. [CrossRef]

119. Betancourt, T.; Pardo, J.; Soo, K.; Peppas, N.A. Characterization of pH-responsive hydrogels of poly(itaconic acid-g-ethylene glycol) prepared by UV-initiated free radical polymerization as biomaterials for oral delivery of bioactive agents. J. Biomed. Mater. Res. A. 2010, 93, 175-188. [CrossRef]

120. Liu, R.; Li, D.; He, B.; Xu, X.; Sheng, M.; Lai, Y.; Wang, G.; Gu, Z. Anti-tumor drug delivery of pH-sensitive poly(ethylene glycol)-poly(L-histidine-)-poly(L-lactide) nanoparticles. J. Control. Release 2011, 152, 49-56. [CrossRef]

121. Xiao, L.; Huang, L.; Moingeon, F.; Gauthier, M.; Yang, G. pH-Responsive poly(ethyleneglycol)-block-polylactide micelles for tumor-targeted drug delivery. Biomacromolecules 2017, 18, 2711-2722. [CrossRef]

122. Gupta, B.; Arora, A.; Saxena, S.; Alam, M.S. Preparation of chitosan-polyethylene glycol coated cotton membranes for wound dressings: Preparation and characterization. Polym. Adv. Technol. 2009, 20, 58-65. [CrossRef]

123. Swift, T.; Swanson, L.; Geoghegan, M.; Rimmer, S. The pH-responsive behaviour opoly(acrylic acid) in aqueous solution is dependent on molar mass. Soft Matter 2016, 12, 2542-2549. [CrossRef]

124. Bromberg, L. Intelligent hydrogels for the oral delivery of chemotherapeutics. Expert. Opin. Drug Deliv. 2005, 2, 1003-1013. [CrossRef]

125. Liu, L.; Yao, W.D.; Rao, Y.F.; Lu, X.Y.; Gao, J.Q. pH-Responsive carriers for oral drug delivery: Challenges and opportunities of current platforms. Drug Deliv. 2017, 24, 569-581. [CrossRef] 
126. Gao, X.; He, C.; Xiao, C.; Zhuang, X.; Chen, X. Synthesis and characterization of biodegradable pH-sensitive poly(acrylic acid) hydrogels crosslinked by 2-hydroxyethyl methacrylate modified poly(L-glutamic acid). Mater. Lett. 2012, 77, 74-77. [CrossRef]

127. Li, G.; Song, S.; Guo, L.; Ma, S. Self-Assembly of thermo- and pH-responsive poly(acrylic acid)-b-poly( $N$-isopropylacrylamide) micelles for drug delivery. J. Polym. Sci. A1. 2008, 46, 5028-5035. [CrossRef]

128. Tian, B.; Liu, S.; Wu, S.; Lu, W.; Wang, D.; Jin, L.; Hu, B.; Li, K.; Wang, Z.; Quan, Z. pH-responsive poly (acrylic acid)-gated mesoporous silica and its application in oral colon targeted drug delivery for doxorubicin. Colloid. Surface B 2017, 154, 287-296. [CrossRef] [PubMed]

129. Gao, X.; He, C.; Xiao, C.; Zhuang, X.; Chen, X. Biodegradable pH-responsive polyacrylic acid derivative hydrogels with tunable swelling behavior for oral delivery of insulin. Polymer 2013, 54, 1786-1793. [CrossRef]

130. Pasche, S.; Angeloni, S.; Ischer, R.; Liley, M.; Luprano, J.; Voirin, G. Wearable biosensors for monitoring wound healing. Adv. Sci. Technol. 2008, 57, 80-87. [CrossRef]

131. Deen, G.R.; Loh, X.J. Stimuli-responsive cationic hydrogels in drug delivery applications. Gels 2018, 4, 13. [CrossRef]

132. Lim, Y.B.; Kim, S.M.; Lee, Y.; Lee, W.K.; Yang, T.G.; Lee, M.J.; Suh, H.; Park, J.S. Cationic hyperbranched poly(amino ester): A novel class of DNA condensing molecule with cationic surface, biodegradable three-dimensional structure, and tertiary amine group in the interior. J. Am. Chem. Soc. 2001, 123, 2460-2461. [CrossRef]

133. Car, A.; Baumann, P.; Duskey, J.T.; Chami, M.; Bruns, N.; Meier, W. pH-responsive PDMS-b-PDMAEMA micelles for intracellular anticancer drug delivery. Biomacromolecules 2014, 15, 3235-3245. [CrossRef]

134. Wu, W.; Liu, J.; Cao, S.; Tan, H.; Li, J.; Xu, F.; Zhang, X. Drug release behaviors of a $\mathrm{pH}$ sensitive semi-interpenetrating polymer network hydrogel composed of poly(vinylalcohol) and star poly 2-(dimethylamino)ethyl methacrylate. Int. J. Pharmaceut. 2011, 416, 104-109. [CrossRef] [PubMed]

135. Oishi, M.; Hayashi, H.; Iijima, M.; Nagasaki, Y. Endosomal release and intracellular delivery of anticancer drugs using pH-sensitive PEGylated nanogels. J. Mater. Chem. 2007, 17, 3720-3725. [CrossRef]

136. Wang, D.; Tan, J.; Kang, H.; Ma, L.; Jin, X.; Liu, R.; Huang, Y. Synthesis, self-assembly and drug release behaviors of $\mathrm{pH}$-responsive copolymers ethyl cellulose-graft-PDEAEMA through ATRP. Carbohyd. Polym. 2011, 84, 195-202. [CrossRef]

137. Ou, K.; Wu, X.; Wang, B.; Meng, C.; Dong, X.; He, J. Controlled in situ graft polymerization of DMAEMA onto cotton surface via SI-ARGET ATRP for low-adherent wound dressings. Cellulose 2017, 24, 5211-5224. [CrossRef]

138. Akhgari, A.; Tavakol, A. Prediction of optimum combination of Eudragit RS/Eudragit RL/ethyl cellulose polymeric free films based on experimental design for using as a coating system for sustained release theophylline pellets. Adv. Pharm. Bull. 2016, 6, 219-225. [CrossRef] [PubMed]

139. Cetin, M.; Atila, A.; Kadioglu, Y. Formulation and in vitro characterization of Eudragit ${ }^{\circledR}$ L100 andEudragit ${ }^{\circledR}$ L100-PLGA nanoparticles containing diclofenac sodium. AAPS Pharm. Sci. Tech. 2010, 11, 1250-1256. [CrossRef] [PubMed]

140. Mady, O. Ibuprofen encapsulation by Eudragit RS100 as microspheres: Preparation and drug release. MOJ Bioequiv. Availab. 2017, 4, 193-199. [CrossRef]

141. Leo, V.D.; Milano, F.; Mancini, E.; Comparelli, R.; Giotta, L.; Nacci, A.; Longobardi, F.; Garbetta, A.; Agostiano, A.; Catucci, L. Encapsulation of curcumin-loaded liposomes for colonic drug delivery in a $\mathrm{pH}$-responsive polymer cluster using a pH-driven and organic solvent-free process. Molecules 2018, 23, 739. [CrossRef]

142. Tipre, D.; Vavia, P. Formulation optimization and stability study of transdermal therapeutic system of nicorandil. Pharm. Dev. Technol. 2002, 7, 325-332. [CrossRef]

(C) 2019 by the authors. Licensee MDPI, Basel, Switzerland. This article is an open access article distributed under the terms and conditions of the Creative Commons Attribution (CC BY) license (http://creativecommons.org/licenses/by/4.0/). 